\title{
SEKTOR UNGGULAN SUMATERA SELATAN DENGAN PENDEKATAN MODEL LOCATION QUOTIENT DAN SHIFT-SHARE
}

\section{SOUTH SUMATERA LEADING SECTOR USING THE LOCATION QUOTIENT AND SHIFT-SHARE MODEL APPROACH}

\author{
Hendrixon Hatta $\left.{ }^{1 *}\right)$ \\ 1)Badan Penelitian dan Pengembangan Daerah Provinsi Sumatera Selatan \\ Jln. Demang Lebar Daun No.4864 Palembang \\ *E-mail : hendrixonhatta@gmail.com
}

Submit : 15 April 2020; Revisi : 28 Juli 2020 ; Terbit : 29 Juli 2020

\begin{abstract}
Every regional government in Indonesia has increased its economic competitiveness. The regional government of South Sumatra Province attempts to increase the value of gross regional domestic product (GRDP) in each business sector and fiscal year so that it can prioritize the sector to achieve the economic improvement target. In this study, the the primary leading sectors will be ranked as a policy input to the the Government of South Sumatra Province. Leading sectors must be developed in South Sumatra to support each regional organization's program. The government policy of South Sumatra which is included in the activity programs of the regional apparatus organizations attempts to support and develop the primary leading sectors, namely, the mining and quarrying industry and the secondary sectors are the real estates and the tertiary sectors such as providing accommodation and food as well as drink that were selected in this study because it contributed to the growth significantly.
\end{abstract}

Keywords: Leading Sector, GRDP, LQ, Shift-Share

\begin{abstract}
ABSTRAK
Peningkatan daya saing ekonomi telah dilakukan oleh setiap daerah di Indonesia. Pemerintah daerah Provinsi Sumatera Selatan berusaha meningkatkan nilai produk domestik regional bruto (PDRB) pada setiap sektor lapangan usaha dan tahun fiskal sehingga prioritas sektor tersebut dapat dikelola pemerintah daerah untuk mencapai target peningkatan ekonomi. Pada studi ini, pemeringkatan sektor primer unggulan akan dilakukan sebagai masukan untuk kebijakan Pemerintah Provinsi Sumatera Selatan. Sektor-sektor unggulan harus dikembangkan di Sumatera Selatan dengan dukungan program setiap organisasi perangkat daerah. Kebijakan pemerintah Sumatera Selatan yang termasuk dalam program kegiatan organisasi perangkat daerah dilaksanakan dalam upaya mendukung dan mengembangkan sektor primer unggulan yaitu industri pertambangan dan penggalian dan sektor sekunder adalah real estate serta sektor tersier seperti penyediaan akomodasi dan makan minum yang dipilih dalam penelitian ini karena memberikan kontribusi pertumbuhan yang signifikan.
\end{abstract}

Kata kunci: Sektor Unggulan, PDRB, LQ, Shift-Share.

\section{PENDAHULUAN}

Perekonomian Provinsi Sumatera Selatan berdasarkan besaran Produk Domestik Regional Bruto (PDRB) atas dasar harga berlaku tahun 2018 mencapai $\mathrm{Rp} 419,72$ triliun dan atas dasar harga konstan 2010 mencapai Rp 298,57 triliun (BPS, 2019). Sumatera Selatan pada tahun 2018 merupakan provinsi yang memiliki ratarata pertumbuhan ekonomi di atas pertumbuhan ekonomi secara nasional yaitu $6,04 \%$ sedangkan pertumbuhan ekonomi nasional sebesar 5,17\%. Laju pertumbuhan ekonomi di atas nasional ini dibukukan oleh provinsi Sumatera Selatan selama 3 (tiga) tahun berturutturut yaitu, pada tahun 2016, 2017, dan 2018 (BPS, 2019). Laju 
pertumbuhan ekonomi tahunan antara Sumatera Selatan dan Indonesia dapat dilihat pada Gambar 1.

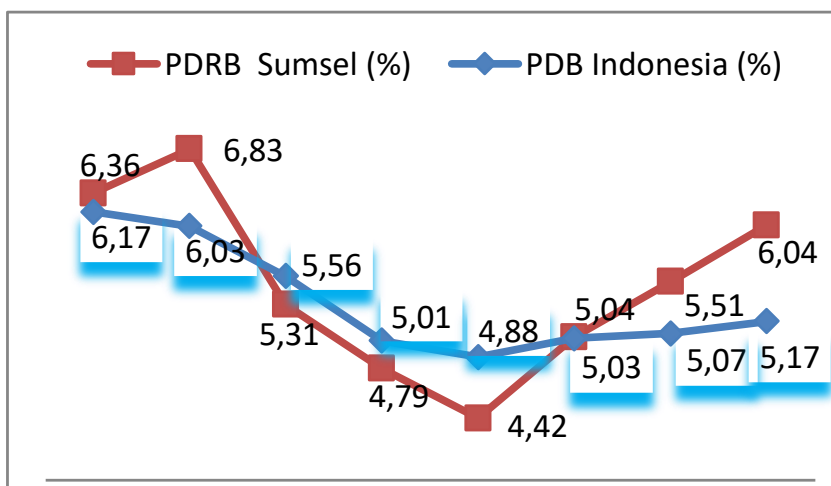

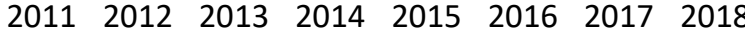

Sumber: BPS, 2019

Gambar 1. Laju Pertumbuhan Ekonomi Tahunan

Menurut data BPS (2019) ada 17 (tujuh belas) sektor yang menjadi pembentuk dari PDRB suatu wilayah. Pertumbuhan ekonomi Sumatera Selatan didukung struktur PDRB yang memiliki beberapa sektor sebagai unsur utama maupun unsur penunjang yang terdiri dari beberapa sektor unggulan terutama pada 3 (tiga) tahun terakhir memiliki konsistensi dari sektor yang sama atau muncul dari sektor lain.

Sektor unggulan adalah sektor yang mampu mendorong pertumbuhan atau perkembangan bagi sektor-sektor lainnya, baik sektor yang mendukung di hulu maupun sektor hilir dalam proses produksinya (Widodo, 2006). Kekuatan ekonomi suatu daerah ditentukan oleh sektor unggulan daerah tersebut (Munandar et al., 2019).

Dalam penelitian sebelumnya PDRB, tingkat inflasi dan belanja daerah digunakan sebagai varaibel penelitian dalam mempengaruhi kesempatan kerja di Sulawesi Utara (Kairupan, 2013). Menurut Wahyuningsih (2016), PDRB dan jumlah penduduk berpengaruh kepada tingkat kemiskinan di Kabupaten Nagan Raya. Pengembangan daerah dilakukan berdasarkan sektor unggulan dan komoditas unggulan (Darlen et al., 2015). Sektor unggulan memiliki potensi lebih cepat tumbuh daripada sektor lainnya dalam suatu daerah (Nurlina et al., 2019). Sektor unggulan dapat mengurangi ketimpangan pembangunan wilayah (Baransano et al., 2016).

Beberapa penelitian yang mengambil objek penelitian di wilayah provinsi Sumatera Selatan yaitu, penelitian mengenai identifikasi sektor dominan di kabupaten Ogan Komering Ilir (OKI) (Basuki \& Gayatri, 2009) dan penelitian yang menggunakan pendekatan Geographic Information System (GIS) untuk mengetahui sektor unggulan dari kabupaten dan kota di Provinsi Sumatera Selatan (Saputri \& Boedi, 2018).

Penelitian ini menggunakan variabel PDRB lapangan usaha untuk menentukan sektor unggulan di Provinsi Sumatera Selatan. Metodenya adalah Location Quotient (LQ) dan Analisis Shift share.

Location Quotient (LQ) adalah perbandingan peran sektor/industri di suatu daerah terhadap besarnya peran sektor/industri tersebut secara nasional (Tarigan, 2005). Sektor/industri yang diperbandingkan di daerah harus sama dengan sektor/industri secara nasional dan waktu perbandingan juga harus sama. Misalnya, sektor konstruksi tahun 2018 di Sumatera Selatan harus diperbandingkan dengan sektor konstruksi nasional tahun 2018 juga.

Analisis shift share umumnya dipakai untuk menganalisis peranan suatu sektor ataupun pergeseran suatu sektor di daerah terhadap sektor yang sama dalam perekonomian nasional. Data yang sering dianalisis adalah data yang terkait kegiatan ekonomi ataupun ketenagakerjaan (Putra, 2011). Senada dengan pendapat tersebut, analisis shift share digunakan untuk membandingkan perbedaan laju pertumbuhan sektor/industri di wilayah 
yang sempit disebut daerah dengan wilayah yang lebih luas disebut nasional (Tarigan, 2005).

Suatu daerah yang memiliki
banyak sektor yang tingkat pertumbuhannya lamban maka sektor tersebut pertumbuhannya secara nasional juga akan lamban. Hal ini terjadi karena daerah-daerah lain tumbuh lebih cepat (Putra, 2011).

\section{METODE}

Penelitian ini menggunakan data sekunder mengenai PDRB Provinsi Sumatera Selatan dibandingkan dengan PDB atas harga konstan menurut lapangan usaha time-series 2014-2018 (BPS, 2019). Selanjutnya dari pemahaman tentang sektor unggulan yang ada di Sumatera Selatan dilakukan analisis dengan menggunakan metode $\mathrm{LQ}$ dan shift share kemudian dilakukan pemeringkatan sektor atau lapangan usaha dan konsistensi sektor yang menjadi unggulan di Sumatera Selatan.

LQ umumnya dipakai untuk melihat perbandingan subregional dengan regional atau regional dengan nasional. Rumus LQ sebagai berikut (Putra, 2011):

$L Q=\frac{X_{i r} / X_{r}}{X_{i n} / X_{n}}$

Keterangan:

$X_{\text {ir }}=$ PDRB sektor i Sumatera Selatan

$X_{r}=$ PDRB Sumatera Selatan

$X_{\text {in }}=$ PDRB sektor $i$ Indonesia

$X_{n}=$ PDRB Indonesia

Nilai dari $L Q$ :

a) $L Q>1$, peranan sektor tersebut lebih besar di regional dibandingkan nasional. Angka ini juga mengindikasikan adanya surplus sehingga dapat dilakukan ekspor,

b) $L Q<1$, peranan sektor tersebut lebih kecil dibandingkan nasional, karena itu memungkinkan dilakukan impor.

c) $L Q=1$, peranan sektor tersebut di regional sama dengan nasional, berimbang

Analisa shift share umumnya digunakan untuk menganalisa suatu sektor ataupun pergeseran suatu sektor di daerah terhadap sektor yang sama dalam perekonomian nasional. Analisa shift share memiliki 3 komponen (Tarigan, 2005):

a. National share, untuk mengetahui pergeseran struktur perekonomian suatu daerah yang dipengaruhi pergeseran perekonomian nasional, menggunakan rumus sebagai berikut:

$N_{i j}=E_{i j} \cdot r_{n}$

b. Proportional shift adalah pertumbuhan nilai tambah bruto suatu sektor dibandingkan dengan total sektor di tingkat nasional, menggunakan rumus sebagai berikut:

$$
M_{i j}=E_{i j}\left(r_{i n}-r_{n}\right)
$$

c. Differential shift adalah perbedaan pertumbuhan perekonomian satu daerah dengan nilai tambah bruto sektor yang sama di tingkat nasional, menggunkan rumus sebagai berikut:

$C_{i j}=E_{i j}\left(r_{i j}-r_{i n}\right)$

Sehingga diperoleh perhitungan analisis shift-share menggunakan rumus sebagai berikut:

$$
D_{i j}=N_{i j}+M_{i j}+C_{i j}
$$


Keterangan:

$D_{i j}$ adalah perubahan sektor i di daerah j (Sumsel)

$\mathrm{N}_{\mathrm{ij}}$ adalah national share

$\mathrm{M}_{\mathrm{ij}}$ adalah proportional shift

$\mathrm{C}_{\mathrm{ij}}$ adalah differential shift.
HASIL DAN PEMBAHASAN

Berdasarkan data PDRB
Sumatera Selatan dan PDB
Indonesia dapat diketahui Location
Quotient masing-masing sektor (lihat
tabel 1).

Tabel 1. Nilai Location Quotient Masing-Masing Sektor Usaha di Sumatera Selatan

\begin{tabular}{|c|c|c|c|c|c|c|}
\hline \multirow[b]{2}{*}{ Lapangan Usaha } & \multicolumn{6}{|c|}{ LQ Sumatera Selatan } \\
\hline & 2014 & 2015 & 2016 & 2017 & 2018 & rerata \\
\hline A. Pertanian, Kehutanan, dan Perikanan & 1,42 & 1,41 & 1,38 & 1,33 & 1,30 & 1,37 \\
\hline B. Pertambangan dan Penggalian & 2,30 & 2,47 & 2,52 & 2,62 & 2,78 & 2,54 \\
\hline C. Industri Pengolahan & 0,83 & 0,83 & 0,85 & 0,86 & 0,86 & 0,84 \\
\hline D. Pengadaan Listrik dan Gas & 0,08 & 0,08 & 0,09 & 0,09 & 0,09 & 0,09 \\
\hline E. Pengadaan Air, Pengelolaan Sampah, Limbah dan Daur Ulang & 1,33 & 1,42 & 1,31 & 1,31 & 1,31 & 1,34 \\
\hline F. Konstruksi & 1,18 & 1,11 & 1,14 & 1,15 & 1,13 & 1,14 \\
\hline G. Perdagangan Besar dan Eceran; Reparasi Mobil dan Sepeda Motor & 0,69 & 0,70 & 0,72 & 0,74 & 0,75 & 0,72 \\
\hline H. Transportasi dan Pergudangan & 0,46 & 0,47 & 0,47 & 0,46 & 0,46 & 0,47 \\
\hline I. Penyediaan Akomodasi dan Makan Minum & 0,37 & 0,38 & 0,40 & 0,41 & 0,44 & 0,40 \\
\hline J. Informasi dan Komunikasi & 0,66 & 0,65 & 0,64 & 0,62 & 0,62 & 0,64 \\
\hline K. Jasa Keuangan dan Asuransi & 0,68 & 0,66 & 0,64 & 0,62 & 0,60 & 0,64 \\
\hline L. Real Estate & 0,92 & 0,94 & 0,97 & 1,00 & 1,03 & 0,97 \\
\hline M,N. Jasa Perusahaan & 0,06 & 0,06 & 0,06 & 0,06 & 0,06 & 0,06 \\
\hline O. Administrasi Pemerintahan, Pertahanan dan Jaminan Sosial Wajib & 0,90 & 0,95 & 0,92 & 0,95 & 0,90 & 0,92 \\
\hline P. Jasa Pendidikan & 0,89 & 0,90 & 0,88 & 0,85 & 0,82 & 0,87 \\
\hline Q. Jasa Kesehatan dan Kegiatan Sosial & 0,61 & 0,62 & 0,59 & 0,57 & 0,54 & 0,59 \\
\hline $\mathrm{R}, \mathrm{S}, \mathrm{T}, \mathrm{U}$. Jasa lainnya & 0,50 & 0,48 & 0,45 & 0,44 & 0,43 & 0,46 \\
\hline \multicolumn{7}{|l|}{ Keterangan : } \\
\hline Nilai LQ Sektor Lapangan Usaha Unggulan (>1) & Angka & & & & & \\
\hline Nilai LQ Sektor Lapangan Usaha Non-Unggulan $(<1)$ & Angka & & & & & \\
\hline
\end{tabular}

Sumber: BPS, Hasil Pengolahan Data 2019

Dari informasi tabel 1 diatas, yang memiliki nilai $L Q>1$ adalah sektor pertanian, kehutanan, perikanan, pertambangan, penggalian, pengadaan air, pengelolaan sampah, limbah dan daur ulang serta konstruksi yang menjadi sektor unggulan di Provinsi Sumatera Selatan. Sektorsektor lapangan usaha ini disebut juga sektor basis (sektor dasar) atau sektor komoditas. Catatan lain mengenai hasil LQ ini diketahui sektor real estate pada tahun 2017 dan 2018 mengalami peningkatan menjadi sektor dasar akan tetapi kenaikan tersebut hanya pada 2 (dua) tahun terakhir dari 5 (lima) tahun pengamatan dalam penelitian ini. Sektor keuangan, sektor real estate dan sektor jasa perusahaan memberikan kontribusi positif terhadap peningkatan pendapatan asli daerah Manado (Lomban, P.C, Engka, SM.D, Sumual, 2016).

$\begin{array}{llr}\text { Analisa shift share dapat } \\ \text { dilihat secara berurutan pada Tabel } \\ 2 \text { national share, Tabel } 3 \\ \text { proporsional shift, dan Tabel } & 4 \\ \text { differential shift sebagai berikut: }\end{array}$

77 Jurnal Borneo Akcaya 
Tabel 2. Nilai National Share

Sumatera Selatan

\begin{tabular}{|l|r|}
\hline \multicolumn{1}{|c|}{ Lapangan Usaha } & \multicolumn{1}{c|}{ National } \\
\hline A. Pertanian, Kehutanan, dan Perikanan & \multicolumn{1}{c|}{ Share } \\
\hline B. Pertambangan dan Penggalian & 9.218 .988 \\
\hline C. Industri Pengolahan & 10.528 .833 \\
\hline D. Pengadaan Listrik dan Gas & 8.831 .651 \\
\hline E. Pengadaan Air, Pengelolaan Sampah, Limbah dan Daur Ulang & 44.322 \\
\hline F. Konstruksi & 54.962 \\
\hline G. Perdagangan Besar dan Eceran; Reparasi Mobil dan Sepeda Motor & 5.611 .991 \\
\hline H. Transportasi dan Pergudangan & 4.682 .495 \\
\hline I. Penyediaan Akomodasi dan Makan Minum & 867.220 \\
\hline J. Informasi dan Komunikasi & 544.410 \\
\hline K. Jasa Keuangan dan Asuransi & 1.459 .752 \\
\hline L. Real Estate & 1.260 .818 \\
\hline M,N. Jasa Perusahaan & 1.359 .372 \\
\hline O. Administrasi Pemerintahan, Pertahanan dan Jaminan Sosial Wajib & 50.230 \\
\hline P. Jasa Pendidikan & 1.535 .257 \\
\hline Q. Jasa Kesehatan dan Kegiatan Sosial & 1.357 .418 \\
\hline R,S,T,U. Jasa lainnya & 323.947 \\
\hline
\end{tabular}

Sumber: BPS, Hasil Pengolahan Data 2019

Dari Tabel 2, sektor yang memiliki nilai tertinggi adalah pertambangan dan penggalian dan sektor terendah adalah pengadaan listrik dan gas. Hal ini cukup menjadi perhatian dikarenakan hasil pertambangan belum optimal digunakan dalam pengadaan listrik dan gas di Provinsi Sumatera Selatan. Sektor pertambangan memiliki peranan dalam PDRB, tetapi belum mampu menumbuhkembangkan sektor hulu dan hilir dari lapangan usaha pertambangan (Hidayat et al., 2014).

Dari nilai $L Q$ yang diperoleh dari Tabel 1 ternyata apabila dilihat nilai national share Sumatera Selatan terdapat penambahan sektor lapangan usaha pembentuk PDRB yaitu, sektor industri pengolahan dan perdagangan besar dan eceran serta kehilangan sektor pengadaan air, pengelolaan sampah, limbah dan daur ulang. Perubahan ini disebabkan intervensi pemerintah dan dunia usaha di Sumatera Selatan yang sudah mengakomodasi perencanaan dan pembangunan berwawasan lingkungan. Faktor pencemaran lingkungan berpengaruh terhadap ketersediaan sumber daya alam, sehingga mempunyai pengaruh dalam menentukan tinggi rendahnya PDRB suatu provinsi, dimana semakin rendah kualitas lingkungan suatu provinsi semakin besar nilai PDRB yang dihasilkan karena kegiatan perekonomian yang dilakukan di wilayah provinsi tersebut (Damayanti \& Chamid, 2016) 
Tabel 3. Nilai Proporsional Shift

Sumatera Selatan

\begin{tabular}{|l|r|}
\hline \multicolumn{1}{|c|}{ Lapangan Usaha } & \multicolumn{1}{c|}{$\begin{array}{c}\text { Proportional } \\
\text { Share }\end{array}$} \\
\hline A. Pertanian, Kehutanan, dan Perikanan & $(1.871 .516)$ \\
\hline B. Pertambangan dan Penggalian & $(10.393 .784)$ \\
\hline C. Industri Pengolahan & $(667.727)$ \\
\hline D. Pengadaan Listrik dan Gas & $(13.199)$ \\
\hline E. Pengadaan Air, Pengelolaan Sampah, Limbah dan Daur Ulang & 7.190 \\
\hline F. Konstruksi & 1.990 .178 \\
\hline G. Perdagangan Besar dan Eceran; Reparasi Mobil dan Sepeda Motor & $(667.794)$ \\
\hline H. Transportasi dan Pergudangan & 584.633 \\
\hline I. Penyediaan Akomodasi dan Makan Minum & 65.646 \\
\hline J. Informasi dan Komunikasi & 1.504 .189 \\
\hline K. Jasa Keuangan dan Asuransi & 647.757 \\
\hline L. Real Estate & $(189.023)$ \\
\hline M,N. Jasa Perusahaan & 41.732 \\
\hline O. Administrasi Pemerintahan, Pertahanan dan Jaminan Sosial Wajib & $(142.281)$ \\
\hline P. Jasa Pendidikan & 136.560 \\
\hline Q. Jasa Kesehatan dan Kegiatan Sosial & 141.440 \\
\hline R,S,T,U. Jasa lainnya & 364.166 \\
\hline Keterangan : & \\
\hline Nilai Positif Proportional Share Sektor Lapangan Usaha $(>0)$ & Angka \\
\hline Nilai Negatif Proportional Share Sektor Lapangan Usaha (<0) & $($ Angka) \\
\hline
\end{tabular}

Sumber: BPS, Hasil Pengolahan Data 2019

Diketahui dari Tabel 3, lapangan usaha pertanian, kehutanan, perikanan, pertambangan, penggalian, industri pengolahan, pengadaan listrik dan gas, perdagangan besar dan eceran, real estate, administrasi pemerintahan, pertahanan, jaminan sosial wajib memiliki nilai proportional shift negatif yang berarti bahwa sektor ini memiliki tingkat pertumbuhan lebih lambat dibandingkan dengan pertumbuhan nasional dalam PDRB Sumatera Selatan. Sedangkan sektor pengadaan air, pengelolaan sampah, limbah dan daur ulang, konstruksi, transportasi dan pergudangan, penyediaan akomodasi dan makan minum, informasi dan komunikasi, jasa keuangan dan asuransi, jasa perusahaan, jasa pendidikan, jasa kesehatan dan kegiatan sosial dan jasa lainnya memiliki nilai positif artinya dapat menjadi pilihan untuk menjadi sektor unggulan Sumatera Selatan. Pengembangan sektor UKM berdasarkan sektor unggulan daerah ini seperti sektor pertanian dan peternakan dapat dipertimbangkan oleh pemerintah Sumatera Selatan dalam menunjang pertumbuhan ekonomi daerah (Basuki \& Gayatri, 2009; Hatta, 2019). Selain itu, dalam penelitian yang lain diperoleh sektor unggulan Sumatera Selatan berbasis komoditas perkebunan adalah kopi, karet, dan kelapa sawit (Hendrixon \& Ciptomulyono, 2016). 
Tabel 4. Nilai Differential Shift

Sumatera Selatan

\begin{tabular}{|l|r|}
\hline \multicolumn{1}{|c|}{ Lapangan Usaha } & \multicolumn{1}{c|}{$\begin{array}{c}\text { Differential } \\
\text { Share }\end{array}$} \\
\hline A. Pertanian, Kehutanan, dan Perikanan & $(3.371 .943)$ \\
\hline B. Pertambangan dan Penggalian & 12.630 .439 \\
\hline C. Industri Pengolahan & 3.388 .094 \\
\hline D. Pengadaan Listrik dan Gas & 57.164 \\
\hline E. Pengadaan Air, Pengelolaan Sampah, Limbah dan Daur Ulang & $(1.746)$ \\
\hline F. Konstruksi & $(480.885)$ \\
\hline G. Perdagangan Besar dan Eceran; Reparasi Mobil dan Sepeda Motor & 3.330 .427 \\
\hline H. Transportasi dan Pergudangan & 155.942 \\
\hline I. Penyediaan Akomodasi dan Makan Minum & 714.678 \\
\hline J. Informasi dan Komunikasi & $(331.499)$ \\
\hline K. Jasa Keuangan dan Asuransi & $(819.200)$ \\
\hline L. Real Estate & 1.204 .903 \\
\hline M,N. Jasa Perusahaan & $(12.134)$ \\
\hline O. Administrasi Pemerintahan, Pertahanan dan Jaminan Sosial Wajib & 224.729 \\
\hline P. Jasa Pendidikan & $(521.815)$ \\
\hline Q. Jasa Kesehatan dan Kegiatan Sosial & $(220.362)$ \\
\hline R,S,T,U. Jasa lainnya & $(333.146)$ \\
\hline Keterangan : & \\
\hline Nilai Positif Differential Share Sektor Lapangan Usaha $(>0)$ & Angka \\
\hline Nilai Negatif Differential Share Sektor Lapangan Usaha (<0) & $($ Angka) \\
\hline
\end{tabular}

Sumber: BPS, Hasil Pengolahan Data 2019

Apabila melihat informasi dari Tabel 4, diperoleh 9 (sembilan) sektor lapangan usaha yang memiliki nilai negatif yang berarti sektor ini kurang menguntungkan dibandingkan 8 (delapan) sektor lapangan usaha yang bernilai positif dari total 17 (tujuh belas) sektor lapangan usaha dalam perkembangan PDRB Sumatera Selatan. Tingginya nilai PDRB di suatu daerah menunjukkan pertumbuhan ekonomi yang baik di daerah tersebut (Dama, YM; Lapian, A ; Sumual, 2016).

Dari hasil penelitian ini, peneliti berusaha untuk mengetahui sektor lapangan usaha yang memiliki kontribusi yang lebih banyak terhadap serapan tenaga kerja dalam pemenuhan sektor lapangan usaha. PDRB memiliki pengaruh signifikan terhadap penyerapan tenaga kerja sektor konstruksi (Fachreza, 2017). Untuk itu, dalam penelitian ini penggunaan data BPS dilakukan pemeringkatan berdasarkan lapangan usaha mengenai struktur PDRB dan pertumbuhan ekonomi yang terjadi dari tahun ke tahun dari setiap sektor seperti dilihat pada Tabel 5 sebagai berikut: 
Tabel 5. Peringkat Lapangan Usaha Berdasarkan Kriteria Sektor Unggulan Yang Digunakan Dalam Penelitian PDRB Di Sumatera Selatan

\begin{tabular}{|c|c|c|c|c|}
\hline & Struktur & Peringkat & Pertumbuhan & Peringkat \\
\hline & PDRB & PDRB & Ekonomi & Pertumbuhan \\
\hline Lapangan Usaha & ADHB (\%) & ADHB & year to year $(\%)$ & Ekonomi \\
\hline A. Pertanian, Kehutanan, dan Perikanan & 14,80 & 3 & 2,16 & 16 \\
\hline B. Pertambangan dan Penggalian & 20,24 & 1 & 9,27 & 3 \\
\hline C. Industri Pengolahan & 19,52 & 2 & 5,51 & 12 \\
\hline D. Pengadaan Listrik dan Gas & 0,13 & 16 & 8,85 & 5 \\
\hline E. Pengadaan Air, Pengelolaan Sampah, Limbah dan Daur Ulang & 0,12 & 17 & 7,96 & 7 \\
\hline F. Konstruksi & 12,98 & 5 & 5,59 & 11 \\
\hline G. Perdagangan Besar dan Eceran; Reparasi Mobil dan Sepeda Motor & 12,94 & 4 & 8,09 & 6 \\
\hline H. Transportasi dan Pergudangan & 2,37 & 10 & 7,36 & 10 \\
\hline I. Penyediaan Akomodasi dan Makan Minum & 1,76 & 12 & 13,15 & 1 \\
\hline J. Informasi dan Komunikasi & 2,85 & 8 & 7,73 & 9 \\
\hline K. Jasa Keuangan dan Asuransi & 2,54 & 9 & 1,78 & 17 \\
\hline L. Real Estate & 3,07 & 6 & 7,95 & 8 \\
\hline M,N. Jasa Perusahaan & 0,13 & 15 & 9,51 & 2 \\
\hline O. Administrasi Pemerintahan, Pertahanan dan Jaminan Sosial Wajib & 2,85 & 7 & 2,70 & 14 \\
\hline P. Jasa Pendidikan & 2,36 & 11 & 2,72 & 13 \\
\hline Q. Jasa Kesehatan dan Kegiatan Sosial & 0,59 & 14 & 2,56 & 15 \\
\hline $\mathrm{R}, \mathrm{S}, \mathrm{T}, \mathrm{U}$. Jasa lainnya & 0,76 & 13 & 9,06 & 4 \\
\hline
\end{tabular}

Keterangan Warna :

Peringkat Lapangan Usaha Pembentuk Struktur PDRB ADHB dan Peringkat Pertumbuhan Ekonomi 1-5

Peringkat Lapangan Usaha Pembentuk Struktur PDRB ADHB dan Peringkat Pertumbuhan Ekonomi 6-10

Peringkat Lapangan Usaha Pembentuk Struktur PDRB ADHB dan Peringkat Pertumbuhan Ekonomi 11-17

Sumber : BPS, Hasil Pengolahan Data 2019

Dari Tabel 5 diperoleh sektor lapangan usaha primer di Sumatera Selatan yaitu, pertambangan dan penggalian; industri pengolahan; pertanian, kehutanan, dan perikanan; perdagangan besar dan eceran; konstruksi sedangkan sektor lapangan usaha sekunder diperoleh real estate; administrasi pemerintahan, pertahanan, dan jaminan sosial wajib; informasi dan komunikasi; jasa keuangan dan asuransi; transportasi dan pergudangan selanjutnya sektor usaha tersier adalah jasa pendidikan; penyediaan akomodasi dan makan minum; jasa lainnya; jasa kesehatan dan kegiatan sosial; jasa perusahaan; pengadaan listrik dan gas; pengadaan air, pengelolaan sampah, limbah, dan daur ulang. Ada fenomena menarik yang ditemukan dalam penelitian ini yaitu, sektor primer yang menjadi unggulan tidak berbanding lurus dengan pertumbuhan ekonomi yang dihasilkan. Selama ini fokus pemerintah berada di sektor lapangan primer, tetapi dalam penelitian ini diperoleh bahwa sektor tersier memberikan tren pertumbuhan ekonomi yang cukup tinggi terhadap PDRB Sumatera Selatan. Namun demikian, sektor pertambangan dan penggalian merupakan sektor yang memiliki keunggulan dan konsistensi dalam kontribusi PDRB Sumatera Selatan serta pertumbuhan ekonomi dari tahun ke tahun.

\section{KESIMPULAN}

Hasil nilai LQ sektor yang dapat dijadikan unggulan Sumatera Selatan adalah pertambangan dan penggalian, pertanian, kehutanan, perikanan, pengadaan air, pengelolaan sampah, limbah dan daur ulang; dan konstruksi.

Jika dari analisis shift share diperoleh national share, maka 
diperoleh 5 (lima) sektor unggulan Sumatera Selatan yaitu, pertambangan dan penggalian; pertanian, kehutanan, perikanan; industri pengolahan; konstruksi; dan perdagangan besar dan eceran. Proportional share Sumatera Selatan menunjukkan sektor pengadaan air, pengelolaan sampah, limbah dan daur ulang; konstruksi; transportasi dan pergudangan; penyediaan akomodasi dan makan minum; informasi dan komunikasi; jasa keuangan dan asuransi; jasa perusahaan; jasa pendidikan; jasa kesehatan dan kegiatan sosial; serta jasa lainnya. Dari hasil differential share, diperoleh sektor pertambangan dan penggalian; industri pengolahan; pengadaan listrik dan gas; perdagangan besar dan eceran; transportasi dan pergudangan; penyediaan akomodasi dan makan minum; real estate; serta administrasi pemerintahan, pertahanan, dan sosial wajib.

Hasil pemeringkatan memberikan informasi lapangan usaha mana saja yang dikategorikan sebagai sektor unggulan dan konsisten pertumbuhan ekonominya adalah sektor pertambangan dan penggalian.

\section{REKOMENDASI}

Penulis memberikan saran kepada pemerintah provinsi Sumatera Selatan untuk mempertimbangan lapangan usaha unggulan yang ditemukan dalam penelitian ini yaitu, sektor pertambangan dan penggalian untuk menjadi program prioritas daerah di Provinsi Sumatera Selatan.

Pemerintah Sumatera Selatan diharapkan segera membuat regulasi berupa Peraturan Gubernur (PerGub) untuk mendukung sektor unggulan (primer) dan sektor penunjang (sekunder dan tersier) yang memberikan pertumbuhan ekonomi yang signifikan terhadap struktur PDRB Sumatera Selatan.

\section{UCAPAN TERIMA KASIH}

Penulis mengucapkan terima kasih kepada Bapak Dian Novriadhy (Kandidat Doktor) dengan bidang keahlian Demografi Sosial dan seluruh pihak yang telah membantu penulis dalam penelitian ini.

\section{DAFTAR PUSTAKA}

Baransano, M. A., Intan, E., Putri, K., Achzani, N. A., \& Kolopaking, L. (2016). Peranan Sektor Unggulan sebagai Salah Satu Faktor dalam Mengurangi Ketimpangan Pembangunan Wilayah di Provinsi Papua Barat. Jurnal Perencanaan Wilayah Dan Kota, 27(2), 119136.

https://doi.org/10.5614/jrcp.2016.2 7.2.4

Basuki, A. T., \& Gayatri, U. (2009). Penentu Sektor Unggulan Dalam Pembangunan Daerah: Studi Kasus di Kabupaten Ogan Komering Ilir. Jurnal Ekonomi Dan Studi Pembangunan, 10(1), 3450.

https://doi.org/10.18196/jesp.10.1. 1280

BPS. (2019). Badan Pusat Statistik. bps.go.id.

Dama, YM; Lapian, A; Sumual, I. . (2016). Pengaruh Produk Domestik Regional Bruto (Pdrb) Terhadap Tingkat Kemiskinan Di Kota Manado (Tahun 2005-2014). Jurnal Berkala IImiah Efisiensi, 16(3), 549-561.

Damayanti, R., \& Chamid, M. S. (2016). Analisis Pola Hubungan PDRB Dengan Faktor Pencemaran Lingkungan Di Indonesia Menggunakan Pendekatan Geographically Weighted Regression (GWR). 
Jurnal Sains Dan Seni Its, 5(1), 712.http://repository.its.ac.id/51393/

Darlen, M. F., Hadi, S., \& Ardiansyah, M. (2015). Pengembangan Wilayah Berbasis Potensi Unggulan $\mathrm{Di}$ Kabupaten Manggarai Timur Provinsi Ntt Sebagai Daerah Otonom Baru. Jurnal TATA LOKA, 17(1), 37-52.

Fachreza, A. N. (2017). Analisis Penyerapan.Tenaga.Kerja Sektor Konstruksi

Kabupaten/Kota.Provinsi

Jawa.Timur Tahun 2011-2015. Jurnal Ekonomi Pembangunan, 15(2), 157-170.

Hatta, H. (2019). Penentuan Pola Kemitraan Di Science Techno Park (STP) Sumatera Selatan. Publikasi Penelitian Terapan Dan Kebijakan, 2(1), 84-89. https://doi.org/10.46774/pptk.v2i1. 91

Hendrixon, \& Ciptomulyono, U. (2016). Penentuan Dan Pengembangan Komoditas Unggulan Kluster Agroindustri Sub-Sektor Perkebunan Dalam Penguatan Sistem Inovasi Daerah Di Provinsi Sumatera Selatan Dengan Pendekatan Analytical Hierarchy Process (AHP) Dan Analisa SWOT [Tesis-Institut Teknologi Sepuluh Nopember Surabaya]. http://repository.its.ac.id/71014/1/9 114201319-master-theses.pdf

Hidayat, W., Rustiadi, E., \& Kartodihardjo, H. (2014). Dampak Sektor Pertambangan Terhadap Perekonomianwilayah Di Kabupaten Luwu Timur. Jurnal Economia, 10(1), 65-80.

Kairupan, S. P. (2013). Produk Domestik Regional Bruto (Pdrb), Inflasi Dan Belanja Daerah Pengaruhnya Terhadap Kesempatan Kerja Di Sulawesi Utara Tahun 2000-2012. Jurnal
Riset Ekonomi, Manajemen, Bisnis Dan Akuntansi, 1(4), 22062216.

Lomban, P.C, Engka, SM.D, Sumual, I. . (2016). Analisis Pengaruh Sektor Keuangan, Real Estate, Jasa Keuangan, Dan Sektor Jasa-Jasa Terhadap Pendapatan Asli Daerah Di Kota Manado (2005-2015). Jurnal Berkala IImiah Efisiensi, 16(3), 727-735.

Munandar, S., Safwadi, I., \& Najmi, I. (2019). Analisis Sektor Ekonomi Unggulan Dan Potensial Terhadap Perekonomian Di Provinsi Aceh (Periode 2010-2017). SEMDI UNAYA-2019, 661-671.

Nurlina, Andiny, P., \& Sari, M. (2019). Analisis Sektor Unggulan Aceh Bagian Timur. Jurnal Samudra Ekonomi Dan Bisnis, 10(1), 2337.

Putra, M. F. (2011). Studi Kebijakan dan Pemerintahan dalam Perspektif Kuantitatif (Teknik, Metode dan Kebijakan) (1st ed.). Universitas Brawijaya Malang.

Saputri, I., \& Boedi, A. (2018). Analisis Sektor Ekonomi Unggulan Pada Kabupaten/Kota Di Provinsi Sumatera Selatan. Jurnal IImu Ekonomi, 2(2), 217-229.

Tarigan, R. (2005). Ekonomi Regional Teori dan Aplikasi Edisi Revisi. Jakarta: PT Bumi Aksara.

Wahyuningsih, Y. E. (2016). Analisis Pengaruh Produk Domestik Regional Bruto dan Jumlah Penduduk Terhadap Tingkat Kemiskinan di Kabupaten Nagan Raya. Jurnal Ekonomi Dan Kebijakan Publik Indonesia, 1(1), 39-47.

Widodo, T. (2006). Perencanaan pembangunan: aplikasi komputer (era otonomi daerah) (2006th ed.). UPP STIM YKPN Yogyakarta. 